\title{
Pesquisa de Micobactérias Ambientais em água de torneira, luvas e soluções utilizadas em procedimentos cirúrgicos no Hospital Universitário Getúlio Vargas - Manaus/AM
}

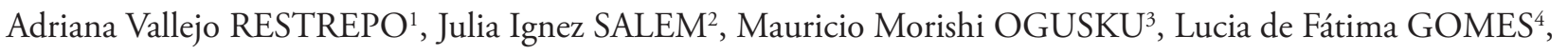
Nelson Abrahim FRAIJI ${ }^{5}$

\section{RESUMO}

Investigou-se por métodos bacteriológicos (cultivo) e moleculares (PCR - Restriction Enzyme Analysis, PRA), a presença de micobactérias ambientais em águas de torneira, soluçôes e luvas cirúrgicas, utilizadas nas etapas dos procedimentos cirúrgicos executados no centro cirúrgico do Hospital Universitário Getulio Vargas (HUGV), na cidade de Manaus-Amazonas/Brasil. Foram colhidas e analisadas 105 amostras sendo: 24 de águas (colhidas das 2 torneiras existentes no centro cirúrgico), 8 de solução de Povidine e 7 de solução de Clorhexidina, que servem para a higienização das mãos dos cirurgiôes; 39 de luvas cirúrgicas (superfícies internas e externas); e 27 de soluçóes que foram efetivamente utilizadas durante o ato cirúrgico. Por método bacteriológico obteve-se 41 isolados micobacterianos apenas de águas das torneiras. Pelo PRA obteve-se a detecçáo de DNA micobacteriano somente na amostra de água que forneceu acima de 100 colônias de micobactérias por tubo semeado. Os isolados foram identificados como sendo Mycobacterium celatum perfil 2, M. gordonae perfil 3, M. gordonae perfil 6, $M$. intracellulare perfil 1, M. lentiflavum perfil 3 e M. mucogenicum perfil 1 . O encontro de M. mucogenicum, espécie já incriminada em surtos pós-cirúrgicos, indica que devem ser efetuados procedimentos de limpeza e monitoramento em todos os pontos de distribuição de águas, visando à prevenção de surtos de micobacterioses nosocomiais induzidos pelo uso das águas nas diferentes atividades de manuseio ou higienização dos pacientes submetidos a procedimentos invasivos.

PALAVRAS-CHAVE: Micobactérias Ambientais, MNT, água, soluçôes anti-sépticas, luvas, procedimentos cirúrgicos.

\section{Investigation of Environmental Mycobacteria in tap water, surgical gloves and antiseptic solutions used in surgical procedures at the Getúlio Vargas University Hospital, Manaus-AM/Brazil}

\begin{abstract}
Using bacteriological (culture) and molecular (PCR - Restriction Enzyme Analysis, PRA) methods, we investigated the presence of environmental mycobacteria in tap water, antiseptic solutions and surgical gloves, used in carrying out surgical procedures at the Getúlio Vargas University Hospital Surgical Center, in Manaus -Amazonas/Brazil. Samples (105) were collected and analyzed from: tap water (24 - collected from 3 taps in the surgical center); povidone-iodine solution, PVP-I, (8); Chlorhexidine solution (7), that were used to hygienize surgeons' hands; surgical gloves (39); and solutions that were effectively used during the surgical procedure (27). Using bacteriological method 41 mycobacteria were isolated, all from samples of tap water. Using PRA, mycobacterial DNA was detected only in the sample from water that provided over 100 colonies per inoculated culture tubes. The isolated were identified as Mycobacterium celatum pattern II, $M$. gordonae pattern III, M. gordonae pattern VI, $M$. intracellulare pattern I, M. lentiflavum pattern III and M. mucogenicum pattern I. The isolating of M. mucogenicum, a species that had already been incriminated for causing post-surgical outbreaks in tap water from the surgical center, indicates that cleaning and monitoring procedures must be carried out in every place of water distribution. This may be necessary to prevent nosological mycobacteriosis outbreaks induced by the use of water in different activities such as handling and hygienizing patients submitted to invasive procedures.
\end{abstract}

KEYWORDS: Environmental mycobacteria, MNT, water, antiseptic solutions, gloves, surgical procedures.

\footnotetext{
1 Universidade Federal do Amazonas - UFAM. E-mail: adrianavallejorestrepo@hotmail.com

2 Instituto Nacional de Pesquisas da Amazônia - INPA. E-mail: salem@inpa.gov.br

3 Instituto Nacional de Pesquisas da Amazônia - INPA. E-mail: mmogusku@inpa.gov.br

${ }^{4}$ Universidade Federal do Amazonas - UFAM. E-mail: luciagomes@hotmail.com

${ }^{5}$ Universidade Federal do Amazonas - UFAM. E-mail: ptropical@ufam.edu.br
} 


\section{INTRODUÇÃO}

De 1873 até o presente, técnicas que vão desde a taxonomia numérica (Tsukamura, 1966), métodos radiométricos associados à hibridização de sondas de DNA (Ellner et al., 1988), perfis de ácidos micólicos (Leite et al., 1998), seqüênciamento de DNA (Springer et al., 1996; Pai et al., 1997), e testes baseados na PCR, permitiram a identificação de 152 espécies e subespécies no gênero Mycobacterium. As primeiras espécies descobertas foram aquelas que mais afetaram e ainda afetam a saúde do homem: o bacilo de Hansen (1873), denominado de Mycobacterium leprae, e o bacilo de Koch (1882) designado como M. tuberculosis. No gênero, também foram incluídas as micobactérias descritas por Bloom em 1884, vinculadas à colonização transitória ou contaminação das amostras clínicas (apud Ordiz, 2006). A maioria das micobactérias tem sido isolada de diversas fontes ambientais (águas, solos, poeiras e materiais vegetais) e/ou de animais. Algumas são encontradas na própria microbiota epidérmica, dos tratos respiratório e gástrico-intestinal dos seres humanos (Edwards \& Palmer, 1959; Salem et al. 1989a; Salem et al., 1989b). Tal fato fez com que Ruiz Manzano e colaboradores (1998), as denominassem como Micobactérias Ambientais (MA).

A partir do isolamento do $M$. fortuitum em um nódulo em axila, no ano de 1938, por Costa Cruz, ficou evidente que as MA poderiam também ser patógenos humanos. Devido a essa associação, em 1959, Penso (apud Casal, 2003, p. 296) definiu a doença como Micobacteriose, independentemente da espécie micobacteriana responsável pelo quadro clínico produzido.

No Brasil, desde 2005 vêm sendo relatados casos de Micobacterioses pós-cirúrgicas, ocasionadas por MA de crescimentos rápidos, em diferentes estados das regiôes brasileiras. No Estado do Pará (regiāo Norte), entre outubro e dezembro de 2004, de 69 amostras de aspirados e biópsias de lesôes nodulares cutâneas de pacientes que haviam sido submetidos às cirurgias videolaparoscópica e de prótese mamária ou que realizaram mesoterapia, foram isoladas MA de crescimentos rápidos em 43 (Lopes et al., 2005).

$\mathrm{Na}$ regiáo Sudeste, estudo realizado por Sampaio et al. (2006), em Campinas/SP, entre fevereiro de 2003 e abril de 2004, relata que 25 pacientes apresentaram infecçâo do local cirúrgico após mamoplastia. O quadro clínico era sugestivo de micobacterioses com drenagem espontânea da secreção após cicatrização aparente das lesōes. A suspeita diagnóstica foi confirmada mediante o isolamento e identificação bacteriológica e molecular das espécies $M$. fortuitum e $M$. porcinum.

Entre agosto de 2006 e fevereiro de 2007, segundo nota técnica $\mathrm{n}^{\mathrm{o}} .02$ do Ministério da Saúde (Brasil/MS, 2007), ocorreu um surto de infecçôes por M. abscessus e M. fortuitum, no Rio de Janeiro, após procedimentos cirúrgicos. Até o mês de março, ao redor de 156 casos foram notificados, com relato de aparecimento de abscessos cutâneos, em cavidade abdominal e em articulaçôes. Segundo a nota técnica, o surto de micobacteriose ocorreu em pacientes submetidos "a processos cirúrgicos ou cirúrgico-endoscópicos, ou ainda, que se infectaram a partir da disseminação do patógeno originário de um sítio cirúrgico à distância”. Segundo Dalcolmo (2007), já no final do mês de junho o número notificado aumentou para 864 casos suspeitos ou confirmados, oriundos de sete municípios e de 64 hospitais (68\% privados e 32\% públicos). A mesma autora relata que "a experiência do controle da epidemia no Rio de Janeiro auxiliou na detecçáo de surtos em outros estados, existindo hoje casos detectados no Rio Grande do Sul, Mato Grosso, Mato Grosso do Sul, Goiás, Minas Gerais, Pernambuco e Espírito Santo".

Os mais prováveis agentes de contaminação micobacteriana, indutores de surtos de micobacteriose pós-cirúrgica, são a água de serventia hospitalar, matérias, soluçôes e instrumentos utilizados nos procedimentos cirúrgicos (Foz et al., 1978; Gremillion et al., 1983; Wallace-Jr et al., 1998; Sethi et al., 2001; Phillips; Von Reyn, 2001; Winthrop et al., 2002; Mackay et al., 2002). Nesse sentido e visando açôes profiláticas, foi investigada, por métodos bacteriológicos e moleculares, a presença de micobactérias ambientais em águas, soluçóes e luvas cirúrgicas, utilizadas nas etapas de procedimentos cirúrgicos executados no Hospital Universitário Getúlio Vargas (HUGV), pertencente à Universidade Federal do Amazonas (UFAM), na cidade de Manaus/AM.

\section{MATERIAIS E MÉTODOS}

Tendo por base o boletim de previsão cirúrgica emitido pelo HUGV, foram selecionados, por método aleatório sistemático, oito procedimentos cirúrgicos entre o período de 13/06 a 14/09/2006.

\section{AMOSTRAS}

Em cada procedimento cirúrgico foram coletadas, para análises micobacteriológica e molecular, as seguintes amostras: $50 \mathrm{~mL}$ de água de cada uma das três torneiras utilizadas na lavagem das mãos dos cirurgiôes; $10 \mathrm{~mL}$ de cada solução de higienizaçáo das mãos utilizadas pelos cirurgiôes (povidine e clorohexidina); $10 \mathrm{~mL}$ das soluçôes de Iodopolivinilpirrolidona 1\% (PVPI), Soro Fisiológico, Álcool $70^{\circ}$, Álcool Iodado, Solução de Ringer, Água Destilada para Injeção, Álcool 96․ Povidine Degermação Sala Cirúrgica, Povidine Aquoso Sala Cirúrgica, efetivamente utilizadas durante os procedimentos cirúrgicos. Todos os líquidos foram coletados em frascos estéreis, acondicionados em recipiente térmico refrigerado e transportados para o Laboratório de Micobacteriologia do Instituto Nacional de Pesquisas da 
Amazônia (INPA), onde foram processados por métodos bacteriológicos e moleculares.

Também foram coletados os dois pares de luvas utilizados por cada cirurgiáo, visando a análise da superfície de contato com a regiáo anatômica do paciente (luva 1) e a que teve contato direto com as mãos do cirurgião (luva 2). Após a retirada seqüencial pelo médico, cada unidade foi hermeticamente lacrada na parte do punho, utilizando-se presilhas plásticas previamente autoclavadas. Individualmente foram acondicionadas em sacos plásticos estéreis para que as superfícies a serem avaliadas não fossem contaminadas entre si. Os sacos plásticos foram lacrados, identificados de acordo com o lado da mão correspondente e superfície a ser analisada, acondicionados em recipiente térmico refrigerado e transportados para processamento no INPA.

A sistemática de coleta possibilitou que o estudo fosse realizado em distintos momentos e em diferentes soluçôes utilizadas em diversos tipos de cirurgias. Consequentemente, também possibilitou a análise de diferentes amostras de águas e lotes de soluçôes, assim como o teor micobacteriológico pós-cirúrgico das luvas utilizadas pelos cirurgiôes.

\section{PROCEDIMENTOS BACTERIOLÓGICOS}

Todas as águas destiladas e reagentes utilizados nos procedimentos para o isolamento de micobactérias foram previamente submetidos à filtração em membrana estéril de $0,2 \mu \mathrm{m}$ e esterilizados em autoclave, visando eliminar todo e qualquer microrganismo, assim como o DNA dos mesmos. Com a mesma intenção, foram utilizados frascos, sacos, tubos, pipetas e demais recipientes estéreis e descartáveis. Vale destacar que todos os frascos e tubos tinham tampa rosqueável, conforme recomendado pelas normas de Biossegurança para atividades com micobactérias (Brasil, 2005). Além disso, os reagentes e meios de cultivo utilizados foram os indicados pela Organização Mundial de Saúde para o isolamento de micobactérias de secreçôes humanas (WHO, 1998) e os processamentos realizados em Cabine de Segurança Biológica Classe II.

No isolamento de micobactérias das amostras de águas e de soluçôes de higienização das mãos utilizadas pelos cirurgióes, foi adotada a técnica descrita por Salem et al. (1989). Nessa, após centrifugação e adição de $2 \mathrm{~mL}$ de água destilada, alíquota de $1 \mathrm{~mL}$ foi transferida para microtubos de $1,5 \mathrm{~mL}$, na qual foi realizada a pesquisa de DNA micobacteriano por procedimento molecular. No restante da amostra foi adicionado $1 \mathrm{~mL}$ de solução de hidróxido de sódio a $4 \%$, visando eliminar outros microrganismos que não as micobactérias. Após homogeneização em vórtex e repouso de 5 minutos, foram adicionados $30 \mathrm{~mL}$ de água destilada estéril e nova centrifugação foi realizada. $\mathrm{O}$ sobrenadante foi desprezado e ao sedimento adicionado $2 \mathrm{~mL}$ de água destilada e uma gota de azul de bromotimol para verificação da faixa de $\mathrm{pH}$. Na presença de $\mathrm{pH}$ básico (cor azul) foi adicionada solução estéril de ácido clorídrico a 4\%, até que se obtivesse a indicação de $\mathrm{pH}$ na faixa de 6,8 a 7,2 (cor verde-clara). A suspensão neutralizada foi semeada em 4 tubos contendo meio de cultivo de Löwensten-Jensen (L-J) e 2 tubos com meio de Ogawa modificado ( $\mathrm{pH} 6,4)$. Cada tubo foi semeado com $0,2 \mathrm{~mL}$ da suspensão, e posteriormente incubados nas temperaturas de $30^{\circ} \mathrm{C}$ e $37^{\circ} \mathrm{C}$, sendo dois tubos de L-J e 1 de Ogawa para cada temperatura.

Para o isolamento de micobactérias das luvas cirúrgicas foi elaborado um protocolo específico visando a análise de toda a superfície de contato com a região anatômica do paciente (luva 1) e com as mãos dos cirurgióes (luva 2). Assim, em Cabine de Segurança Biológica, as unidades identificadas como luva 1 foram retiradas do saco plástico, e depositadas em placa de Petri. Próximo ao local onde se efetuou o lacramento das luvas e com auxílio de seringas descartáveis, foram injetados em seus interiores $100 \mathrm{~mL}$ de soluçấo de cloreto de cetilpiridinio a $0,05 \%$. As luvas foram agitadas manualmente por 2 minutos para que os possíveis microrganismos existentes no ambiente cirúrgico (contato com a parte anatômica do paciente submetido ao ato cirúrgico) se desprendessem e ficassem imersos na solução utilizada. Posteriormente a soluçáo foi coletada por aspiraçáo com seringa descartável, transferida para tubo cônico e então centrifugada a $4.000 \times g$ por 20 minutos, em centrífuga refrigerada. Os demais procedimentos foram os mesmos relatados para as amostras de águas.

Em cada saco plástico contendo as unidades identificadas como luva 2 e com auxílio de seringa descartável, foram injetados $100 \mathrm{~mL}$ de soluçâo de cloreto de Cetilpiridínio a $0,05 \%$. Os sacos foram agitados manualmente por 2 minutos para que os possíveis microrganismos, existentes na superfície da luva que teve contato com as mãos dos cirurgióes, se desprendessem e ficassem imersos na soluçâo utilizada. Posteriormente, a solução foi aspirada e transferida para tubo cônico e então centrifugada a $4.000 \times \mathrm{g}$ por 20 minutos, em centrífuga refrigerada. Os demais procedimentos foram os mesmos relatados para as amostras de águas.

Os isolados micobacterianos foram estudados quanto as características de álcool-ácido resistência das colônias, velocidade de crescimento, produçáo de pigmentos e de niacina, conforme estabelecido por David et al. (1989).

\section{PROCEDIMENTOS MOLECULARES}

Tanto para a detecção de DNA micobacteriano nos sedimentos das amostras processadas, como para a identificação dos isolados de micobactérias, utilizou-se a técnica de PRA (PCR-Restriction Enzyme Analysis) com amplificação do gene hsp65 e análise do polimorfismo dos fragmentos de restriçáo após digestão, com as enzimas BstEII e HaeIII (Telenti et al., 
1993; Devallois et al., 1997; Silva et al., 2001; Leão et al., 2005).

A extração do DNA dos sedimentos das amostras de líquidos e soluçóes foi realizada de acordo com o protocolo de Silva et al. (2001). Para tanto, um volume de $100 \mu \mathrm{L}$ dos microtubos contendo $1 \mathrm{~mL}$ da amostra centrifugada foi transferido para um microtubo de $1,5 \mathrm{~mL}$ contendo $100 \mu \mathrm{L}$ de tampão TET (10 mM Tris-HCl pH 8,0; 1 mM EDTA; 1\% Triton X-100). A amostra foi incubada a $100^{\circ} \mathrm{C}$ por $10 \mathrm{~min}$, armazenada a $-20^{\circ} \mathrm{C}$ por um pernoite, centrifugada a 12.000 $x g$ por 30 segundos e do sobrenadante $5 \mu \mathrm{L}$ foram submetidos à PCR. Na extraçáo do DNA dos isolados micobaterianos também foi utilizado o protocolo de Silva et al. (2001), tendo sido substituído apenas o uso direto da colônia micobacteriana por uma suspensão padronizada de $1 \mathrm{mg}$ de bacilos $/ \mathrm{mL}$. Assim, em um microtubo de $1,5 \mathrm{~mL}$ foi adicionado $20 \mu \mathrm{L}$ de suspensão micobacteriana contendo $1 \mathrm{mg}$ de bacilos $/ \mathrm{mL}$ e $80 \mu \mathrm{L}$ de TE $(10 \mathrm{mM}$ Tris/HCL, pH 8.0, 1 mM EDTA diluição 1:5). A inativação foi realizada a $80^{\circ} \mathrm{C}$ por 10 minutos $\mathrm{e}$ as amostras centrifugadas (12000 $\times \mathrm{g}$ por 30 segundos) em centrífuga refrigerada. Posteriormente a adição de $100 \mu \mathrm{L}$ de tampão TET (10 mM Tris-HCl pH 8,0; 1 mM EDTA; 1\% Triton X-100), o tubo foi incubado a $100^{\circ} \mathrm{C}$ por 10 minutos e armazenado a $-20^{\circ} \mathrm{C}$ por um pernoite. Após o pernoite, a amostra foi centrifugada a $12.000 \times g$ por 30 segundos e $5 \mu \mathrm{L}$ do sobrenadante foram submetidos à análise pela PCR.

A PCR para confirmação de amplificação de DNA foi realizada conforme Leão et al. (2004), em um volume total de $30 \mu \mathrm{L}$, contendo: $20 \mathrm{mM}$ Tris pH 8,4, $50 \mathrm{mM} \mathrm{KCl}, 1,5 \mathrm{mM}$ $\mathrm{MgCl}_{2}, 120 \mu \mathrm{M}$ dNPTs, $0,1 \mu \mathrm{M}$ de cada primer Tb11 (ACC AAC GAT GGT GTG TCC AT) e Tb 12 (CTT GTC GAA CCG CAT ACC CT), 2 U de Taq DNA Polimerase e $5 \mu \mathrm{L}$ da amostra de DNA extraída. Os parâmetros de amplificação foram: $95^{\circ} \mathrm{C}$ por $5^{\prime} ; 45$ ciclos de $94^{\circ} \mathrm{C}$ por $1^{\prime}, 60^{\circ} \mathrm{C}$ por $1^{\prime} \mathrm{e}$ $72^{\circ} \mathrm{C}$ por 1'; e um ciclo final de $72^{\circ} \mathrm{C}$ por 7 '. Em cada grupo de amplificaçôes foi utilizado como controle positivo DNA de $M$. tuberculosis $\mathrm{H}_{37} \mathrm{Rv}$, e como negativo alíquotas de água ultrapura (tipo I) estéril. Além desses, também foi incluída uma alíquota da mistura de reagentes, sem DNA, para descartar contaminaçôes nos mesmos. Para a confirmação da amplificação do fragmento do gene $h s p 65$ (441 pares de bases), $5 \mu \mathrm{L}$ do produto da PCR foram submetidos à eletroforese em gel de agarose $1,5 \%$.

Após a confirmação de amplificação, duas alíquotas de $10 \mu \mathrm{L}$ do produto da PCR foram digeridas, respectivamente, com $10 \mathrm{U}$ da enzima de restrição BstEII $\left(\mathrm{a} 60^{\circ} \mathrm{C}\right)$ e HaeIII (a $37^{\circ} \mathrm{C}$ ), ambas por 3 horas. Para a visualização dos produtos de digestão, os mesmos foram submetidos a uma eletroforese em gel de agarose a $4 \%$ juntamente com padrões de tamanho de fragmentos de DNA ( 25 e 50 pares de base). A separaçáo eletroforética foi realizada em tampão TBE $(89 \mathrm{mM}$ Tris; $89 \mathrm{mM}$ de ácido bórico; $2 \mathrm{mM}$ de EDTA pH 8,0) a 75 Volts e 40 miliamperes por 4 horas. Posteriormente, o gel de agarose foi corado com brometo de etídeo e visualizado em transiluminador de luz UV e fotografado. Os padróes das bandas do DNA das micobactérias após digestão foram interpretados de acordo com os já descritos para cada espécie micobacteriana por Brunello et al. (2001) e conferidos no site http://app.chuv.ch/prasite/index.html.

\section{RESULTADOS E DISCUSSÃO}

Para a detecção de micobactérias foram obtidas e analisadas, por métodos bacteriológicos e moleculares, 105 amostras cujas origens e tipos, conforme os procedimentos cirúrgicos estão apresentados na Tabela 1 .

Tabela 1 - Quantitativo de amostras obtidas no Hospital Universitário Getúlio Vargas/AM, conforme tipo de amostra e procedimento cirúrgico.

\begin{tabular}{|c|c|c|c|c|c|c|c|c|c|}
\hline \multirow[b]{2}{*}{ Tipo de Amostra } & \multicolumn{9}{|c|}{ Tipo de cirurgia e sala cirúrgica } \\
\hline & $\begin{array}{l}\text { Colecistec- } \\
\text { tomia } \\
13 / 06 / 07\end{array}$ & $\begin{array}{c}\text { Tenotomia } \\
\text { Múltipla de } \\
\text { Flexores } \\
\text { Bilaterais } \\
21 / 06 / 07\end{array}$ & $\begin{array}{c}\text { Cirurgia } \\
\text { Endoscópica } \\
\text { Nasal } \\
28 / 06 / 07\end{array}$ & $\begin{array}{c}\text { Safena e } \\
\text { Varizec-tomia } \\
\text { 10/07/07 }\end{array}$ & $\begin{array}{c}\text { Pleurosco-pia } \\
\text { 19/07/07 }\end{array}$ & $\begin{array}{c}\text { Artrodese } \\
\text { Cervical } \\
\text { Enxerto } \\
24 / 07 / 07\end{array}$ & $\begin{array}{c}\text { Correção } \\
\text { de Fratura } \\
\text { de Coluna } \\
\text { Lombar } \\
\text { 09/09/07 }\end{array}$ & $\begin{array}{c}\text { Hernior-rafia } \\
\text { 14/09/07 }\end{array}$ & Totais \\
\hline Água Torneira 1 & 1 & 1 & 1 & 1 & 1 & 1 & 1 & 1 & 8 \\
\hline Água Torneira 2 & 1 & 1 & 1 & 1 & 1 & 1 & 1 & 1 & 8 \\
\hline Água Torneira 3 & 1 & 1 & 1 & 1 & 1 & 1 & 1 & 1 & 8 \\
\hline $\begin{array}{l}\text { Povidine de lavagem } \\
\text { das mãos }\end{array}$ & 1 & 1 & 1 & 1 & 1 & 1 & 1 & 1 & 8 \\
\hline $\begin{array}{l}\text { Clorohexidina de } \\
\text { lavagem das mãos }\end{array}$ & 1 & 1 & 1 & 1 & 1 & 1 & 0 & 1 & 7 \\
\hline $\begin{array}{l}\text { Lado interno da luva } \\
\text { do Cirurgião }\end{array}$ & 3 & 4 & 2 & 3 & 2 & 2 & 1 & 3 & 20 \\
\hline $\begin{array}{l}\text { Lado externo da luva } \\
\text { do Cirurgião }\end{array}$ & 3 & 3 & 2 & 3 & 2 & 2 & 1 & 3 & 19 \\
\hline PVPI & 1 & 1 & 0 & 1 & 1 & 1 & 0 & 1 & 6 \\
\hline
\end{tabular}




\begin{tabular}{|c|c|c|c|c|c|c|c|c|c|}
\hline \multirow[b]{2}{*}{ Tipo de Amostra } & \multicolumn{9}{|c|}{ Tipo de cirurgia e sala cirúrgica } \\
\hline & $\begin{array}{l}\text { Colecistec- } \\
\text { tomia } \\
13 / 06 / 07\end{array}$ & $\begin{array}{c}\text { Tenotomia } \\
\text { Múltipla de } \\
\text { Flexores } \\
\text { Bilaterais } \\
21 / 06 / 07\end{array}$ & $\begin{array}{c}\text { Cirurgia } \\
\text { Endoscópica } \\
\text { Nasal } \\
28 / 06 / 07\end{array}$ & $\begin{array}{c}\text { Safena e } \\
\text { Varizec-tomia } \\
10 / 07 / 07\end{array}$ & $\begin{array}{c}\text { Pleurosco-pia } \\
\text { 19/07/07 }\end{array}$ & $\begin{array}{l}\text { Artrodese } \\
\text { Cervical } \\
\text { Enxerto } \\
24 / 07 / 07\end{array}$ & $\begin{array}{l}\text { Correção } \\
\text { de Fratura } \\
\text { de Coluna } \\
\text { Lombar } \\
\text { 09/09/07 }\end{array}$ & $\begin{array}{l}\text { Hernior-rafia } \\
\text { 14/09/07 }\end{array}$ & Totais \\
\hline $\begin{array}{l}\text { Soro Fisiológico ou } \\
\mathrm{NaCl} 0,9 \%\end{array}$ & 1 & 1 & 1 & 1 & 1 & 1 & 1 & 1 & 8 \\
\hline Álcool $70^{\circ}$ & 1 & 0 & 0 & 1 & 0 & 0 & 0 & 1 & 3 \\
\hline Álcool lodado & 1 & 1 & 0 & 0 & 0 & 1 & 1 & 0 & 4 \\
\hline Solução de Ringer & 1 & 0 & 0 & 0 & 0 & 0 & 0 & 0 & 1 \\
\hline $\begin{array}{l}\text { Água Destilada para } \\
\text { Injeção }\end{array}$ & 0 & 0 & 0 & 0 & 1 & 1 & 0 & 0 & 2 \\
\hline Álcool 96º & 0 & 0 & 0 & 0 & 0 & 1 & 0 & 0 & 1 \\
\hline $\begin{array}{l}\text { Povidine - Sala } \\
\text { Cirúrgica }\end{array}$ & 0 & 0 & 0 & 0 & 0 & 1 & 0 & 0 & 1 \\
\hline $\begin{array}{l}\text { Povidine Aquoso Sala } \\
\text { Cirúrgica }\end{array}$ & 0 & 0 & 0 & 0 & 0 & 0 & 0 & 1 & 1 \\
\hline Totais & 16 & 15 & 10 & 14 & 12 & 15 & 8 & 15 & 105 \\
\hline
\end{tabular}

$\mathrm{PVPI}=$ Iodopolivinilpirrolidona 1\%; $\mathrm{NaCl}=$ Cloreto de Sódio 0,9\%

Pelo método de cultivo foi obtido o isolamento de micobactérias apenas nas amostras das águas de torneiras. A positividade obtida, conforme as torneiras e as datas de coleta estâo apresentadas na Tabela 2. Foi constatado que existe uma contaminaçáo, ou talvez uma colonizaçáo, por micobactérias no sistema de distribuição de água do Hospital Universitário Getúlio Vargas. Tal fato é respaldado pela presença de micobactérias na maioria de todas as amostras de águas, colhidas em diferentes datas, das três torneiras que servem às diferentes salas do centro cirúrgico. $\mathrm{O}$ resultado indica que o problema pode estar centrado na caixa d'água da referida unidade hospitalar ou ser oriundo do sistema de abastecimento público. os autores obtiveram o dobro de isolados na temperatura de $30^{\circ} \mathrm{C}$ em relaçáo à de $37^{\circ} \mathrm{C}$.

Com relação aos meios de cultivo (Tabela 3), é possível que a diferença encontrada seja devido a utilização de diferentes quantidades de tubos semeados ( 2 de Löwenstein-Jensen para 1 de Ogawa-Kudoh), proporcionando maior quantidade de inoculo em Löwenstein-Jensen e assim, ampliando a possibilidade de isolamento. Entretanto, pode-se deduzir que ambos os meios são adequados para o isolamento de micobactérias em amostras ambientais.

A obtenção de micobactérias foi em média de uma colônia em cada um dos dois tubos semeados (Tabela 3), com exceçáo

Tabela 2 - Isolamento de micobactérias de águas corrente do Hospital Universitário Getúlio Vargas/AM, conforme a torneira e data de coleta.

\begin{tabular}{|c|c|c|c|c|c|c|c|c|}
\hline \multirow{2}{*}{ Amostras de água } & \multicolumn{8}{|c|}{ Datas de coleta no ano de 2007} \\
\hline & $13 / 06$ & $21 / 06$ & $28 / 06$ & $10 / 07$ & $19 / 07$ & $24 / 07$ & $09 / 09$ & $14 / 09$ \\
\hline Torneira 1 & - & Cont. * & + & - & + & + & - & - \\
\hline Torneira 2 & + & Cont. * & + & + & - & + & + & + \\
\hline Torneira 3 & - & Cont. * & + & + & - & + & + & + \\
\hline
\end{tabular}

* = contaminação por outros microrganismos impossibilitando possível isolamento de micobactérias

O isolamento de micobactérias das águas foi obtido conforme os meios de cultivo e temperaturas apresentadas na Tabela 3. Maior quantitativo de isolados micobaterianos foi obtido em amostras incubadas a $30^{\circ} \mathrm{C}$, correspondendo a 25 (61\%) do total de isolamento. A temperatura de $30^{\circ} \mathrm{C}$ tem sido a mais indicada para o isolamento de MA, pois vários autores obtiveram resultados semelhantes aos encontrados no presente trabalho (Neumann et al., 1997). Entre eles merece destaque o de Salem (1987), por ter sido realizado em Manaus, onde das amostras de água da $2^{\mathrm{a}}$ torneira do último ato cirúrgico estudado, que devido à aglomeração foi impossível contá-las. Dos 41 isolados micobacterianos obtidos, a torneira 1 forneceu 4, a 2 propiciou 22 e da 3 foram isolados 15 . O fato indica que no decorrer do trabalho a contaminaçáo, ou talvez a colonização, por micobactérias no sistema de distribuição de água da torneira 2 foi se agravando.

No total, 41 isolados de micobactérias foram obtidos das amostras de águas, cujos resultados dos testes de identificação 
Tabela 3 - Número de isolados e colônias de micobactérias no Hospital Universitário Getúlio Vargas/AM, conforme data e torneira de coleta, meios de cultivo e temperatura de isolamento.

\begin{tabular}{|c|c|c|c|c|c|c|c|c|c|c|c|c|c|}
\hline \multirow{5}{*}{ Datade Coleta } & \multirow{5}{*}{ Torneira } & \multicolumn{8}{|c|}{ Meio de Löwenstein-Jensen } & \multirow{2}{*}{\multicolumn{4}{|c|}{$\begin{array}{c}\text { Meio de Ogawa-Kudoh } \\
\text { Temperaturas }\end{array}$}} \\
\hline & & \multicolumn{8}{|c|}{ Temperaturas } & & & & \\
\hline & & \multicolumn{4}{|c|}{$37^{\circ} \mathrm{C}$} & \multicolumn{4}{|c|}{$30^{\circ} \mathrm{C}$} & \multicolumn{2}{|c|}{$37^{\circ} \mathrm{C}$} & \multicolumn{2}{|c|}{$30^{\circ} \mathrm{C}$} \\
\hline & & \multicolumn{2}{|c|}{ Tubo 1} & \multicolumn{2}{|c|}{ Tubo 2} & \multicolumn{2}{|c|}{ Tubo 1} & \multicolumn{2}{|c|}{ Tubo 2} & \multicolumn{2}{|c|}{ Tubo 1} & \multicolumn{2}{|c|}{ Tubo 1} \\
\hline & & $\begin{array}{l}\mathrm{N}^{0} \text {. de } \\
\text { Isol }\end{array}$ & $\begin{array}{c}N^{0} \text {. de } \\
\text { Col }\end{array}$ & $\begin{array}{l}\mathrm{N}^{0} \text {. de } \\
\text { Isol }\end{array}$ & $\begin{array}{c}\mathrm{N}^{0} \text {. de } \\
\text { Col }\end{array}$ & $\begin{array}{l}\text { NN}^{0} \text {. de } \\
\text { Isol }\end{array}$ & $\begin{array}{c}N^{0} \text {. de } \\
\text { Col }\end{array}$ & $\begin{array}{l}\mathrm{N}^{0} \text {. de } \\
\text { Isol }\end{array}$ & $\begin{array}{c}N^{0} \text {. de } \\
\text { Col }\end{array}$ & $\begin{array}{l}N^{0} \text {. de } \\
\text { Isol }\end{array}$ & $\begin{array}{c}N^{0} \text {. de } \\
\text { Col }\end{array}$ & $\begin{array}{l}\mathrm{N}^{0} \text {. de } \\
\text { Isol }\end{array}$ & $\begin{array}{c}\mathrm{N}^{0} \text {. de } \\
\text { Col }\end{array}$ \\
\hline \multirow{3}{*}{$13 / 06 / 07$} & 1 & 0 & 0 & 0 & 0 & 0 & 0 & 0 & 0 & 0 & 0 & 0 & 0 \\
\hline & 2 & 0 & 0 & 0 & 0 & 0 & 0 & 0 & 0 & 0 & 0 & 1 & 1 \\
\hline & 3 & 0 & 0 & 0 & 0 & 0 & 0 & 0 & 0 & 0 & 0 & 0 & 0 \\
\hline \multirow{3}{*}{$21 / 06 / 07$} & 1 & Cont & Cont & Cont & Cont & Cont & Cont & Cont & Cont & Cont & Cont & Cont & Cont \\
\hline & 2 & Cont & Cont & Cont & Cont & Cont & Cont & Cont & Cont & Cont & Cont & Cont & Cont \\
\hline & 3 & Cont & Cont & Cont & Cont & Cont & Cont & Cont & Cont & Cont & Cont & Cont & Cont \\
\hline \multirow{3}{*}{$28 / 06 / 07$} & 1 & 0 & 0 & 0 & 0 & 0 & 0 & 1 & 1 & 0 & 0 & 0 & 0 \\
\hline & 2 & 0 & 0 & 1 & 1 & 0 & 0 & 0 & 0 & 1 & 1 & 0 & 0 \\
\hline & 3 & 1 & 1 & 0 & 0 & 0 & 0 & 0 & 0 & 0 & 0 & 2 & $1 \mathrm{e} 1$ \\
\hline \multirow{3}{*}{$10 / 07 / 07$} & 1 & 0 & 0 & 0 & 0 & 0 & 0 & 0 & 0 & 0 & 0 & 0 & 0 \\
\hline & 2 & 1 & 2 & 1 & 1 & 1 & 1 & 2 & $1 \mathrm{e} 1$ & 0 & 0 & 1 & 3 \\
\hline & 3 & 1 & 3 & 0 & 0 & 1 & 1 & 1 & 1 & 0 & 0 & 0 & 0 \\
\hline \multirow{3}{*}{$19 / 07 / 07$} & 1 & 0 & 0 & 0 & 0 & 0 & 0 & 0 & 0 & 0 & 0 & 1 & 1 \\
\hline & 2 & 0 & 0 & 0 & 0 & 0 & 0 & 0 & 0 & 0 & 0 & 0 & 0 \\
\hline & 3 & 0 & 0 & 0 & 0 & 0 & 0 & 0 & 0 & 0 & 0 & 0 & 0 \\
\hline \multirow{3}{*}{$24 / 07 / 07$} & 1 & 0 & 0 & 0 & 0 & 1 & 1 & 1 & 1 & 0 & 0 & 0 & 0 \\
\hline & 2 & 2 & $1 \mathrm{e} 1$ & 0 & 0 & 1 & 2 & 0 & 0 & 0 & 0 & 2 & $1 \mathrm{e} 1$ \\
\hline & 3 & 1 & 2 & 0 & 0 & 0 & 0 & 0 & 0 & 0 & 0 & 1 & 1 \\
\hline \multirow{3}{*}{ 09/09/07 } & 1 & 0 & 0 & 0 & 0 & 0 & 0 & 0 & 0 & 0 & 0 & 0 & 0 \\
\hline & 2 & 0 & 0 & 0 & 0 & 1 & 1 & 0 & 0 & 1 & 1 & 0 & 0 \\
\hline & 3 & 1 & 2 & 0 & 0 & 1 & 1 & 1 & 1 & 1 & 1 & 0 & 0 \\
\hline \multirow{3}{*}{$14 / 09 / 07$} & 1 & 0 & 0 & 0 & 0 & 0 & 0 & 0 & 0 & 0 & 0 & 0 & 0 \\
\hline & 2 & 1 & inc & 1 & inc & 1 & inc & 1 & inc & 1 & inc & 1 & inc \\
\hline & 3 & 0 & 0 & 0 & 0 & 1 & 3 & 0 & 0 & 1 & 1 & 1 & 1 \\
\hline \multicolumn{2}{|c|}{ Total de isolados } & \multicolumn{4}{|c|}{11} & \multicolumn{4}{|c|}{15} & \multicolumn{2}{|c|}{5} & & \\
\hline
\end{tabular}

Isol = isolados; Col = colônias; Cont = contaminação por outros microrganismos impossibilitando possível isolamento de micobactérias; inc = incontáveis, correspondendo a mais de 100 colônias/tubo semeado.

fenotípica e molecular foram comparados com os padróes estabelecidos no site http://app.chuv.ch/prasite/index.html, e corresponderam às espécies apresentadas na Tabela 4, sendo o $M$. celatum perfil 2, a espécie mais isolada. Trata-se de uma micobactéria que apresenta semelhança bioquímica com as espécies do complexo MAC (M. avium, M. intracellulare, M. scrofulaceum, $M$. chimaera e $M$. colombiense), e isolada com mais freqüência de pacientes soropositivos para HIV (Bermúdez et al., 2001).

A segunda espécie mais isolada foi o $M$. gordonae, cujas somatórias de seus perfis encontrados correspondeu a 31\% de todos os isolados. Vale ressaltar que o M. gordonae também é conhecido como "escotocromógeno de água de torneira" por ser muito freqüente nos sistemas de abastecimento e distribuição de água (Vaerewijck et al., 2005). Apesar de ser uma micobactéria raramente patogênica já foi indicada como agente etiológico de um caso de micobacteriose em paciente HIV positivo, nos anos $90 \mathrm{em}$ Cuba (Ruiz \& MedeirosCuervo, 1999).

O M. intracellulare foi a terceira espécie mais isolada. É uma micobactéria de crescimento lento, comumente não pigmentada, que junto com o $M$. avium são encontradas 
Tabela 4 - Espécies de micobactérias isoladas de águas de torneiras do centro cirúrgico do Hospital Universitário Getulio Vargas/AM.

\begin{tabular}{|c|c|c|c|c|c|c|c|c|c|c|c|c|c|c|}
\hline \multirow[t]{2}{*}{ Torneiras } & \multicolumn{2}{|c|}{$\begin{array}{l}\text { M. celatum } \\
\text { perfil } 2\end{array}$} & \multicolumn{2}{|c|}{$\begin{array}{l}\text { M. gordonae } \\
\text { perfil } 3\end{array}$} & \multicolumn{2}{|c|}{$\begin{array}{l}\text { M. gordonae } \\
\text { perfil } 6\end{array}$} & \multicolumn{2}{|c|}{$\begin{array}{l}\text { M. intracellulare } \\
\text { perfil } 1\end{array}$} & \multicolumn{2}{|c|}{$\begin{array}{l}\text { M. Ientiflavum } \\
\text { perfil } 3\end{array}$} & \multicolumn{2}{|c|}{$\begin{array}{l}\text { M. mucogenicum } \\
\text { perfil } 1\end{array}$} & \multicolumn{2}{|c|}{ Totais } \\
\hline & $\mathrm{N}^{0}$ & $\%$ & $\mathrm{~N}^{0}$ & $\%$ & $\mathrm{~N}^{0}$ & $\%$ & $\mathrm{~N}^{0}$ & $\%$ & $\mathrm{~N}^{0}$ & $\%$ & $\mathrm{~N}^{0}$ & $\%$ & $\mathrm{~N}^{0}$ & $\%$ \\
\hline $\mathrm{T} 1$ & 3 & 7 & 1 & 2 & - & - & - & - & - & - & - & - & 4 & 9 \\
\hline T2 & 10 & 24 & 4 & 10 & 1 & 2 & 4 & 10 & 2 & 5 & 1 & 2 & 22 & 54 \\
\hline T3 & 6 & 15 & 7 & 17 & - & - & - & - & - & - & 2 & 5 & 15 & 37 \\
\hline Totais & 19 & 46 & 12 & 29 & 1 & 2 & 4 & 10 & 2 & 5 & 3 & 7 & 41 & 100 \\
\hline
\end{tabular}

$\mathrm{T} 1=$ Torneira $1 ; \mathrm{T} 2=$ Torneira 2; $\mathrm{T} 3=$ Torneira $3 ; M=$ Mycobacterium .

no meio ambiente (Leão et al., 2004). Vale ressaltar que os isolados tiveram comportamento fenotípico de produção de pigmento diferente do exposto no site http://app.chuv.ch/ prasite/index.html, pois tiveram o comportamento de espécies escotocromogênicas. Entretanto, tiveram concordância com os padróes dos perfis moleculares, mediante a distribuição e tamanho das bandas na eletroforese. Testes fenotípicos podem variar dependendo das condiçóes de crescimento, sendo alguns resultados não conclusivos (Covert et al., 1999). Segundo Bland et al. (2005), esses testes apresentam variabilidade nos resultados, mesmo quando realizados corretamente, devido ao fato de que os isolados ambientais ocasionalmente apresentam características como temperatura de crescimento ou pigmentaçáo diferente das cepas de referência como resultado da sua adaptação às condiçôes ambientais. Além desses fatos, trabalho sobre taxonomia micobacteriana realizado por Runyon et al. (1980), mostrou que dos isolados de $M$. intracellulare, $85 \%$ são "não cromogênicas", $3 \%$ "fotocromogênicas" e 12\% "escotocromogênicas", dados esses que respaldam a identificação realizada no presente trabalho. Outro fato importante são os padróes fenotípicos de $M$. intracellulare isolados em Manaus/AM por Salem (1987). Dos 36 isolados, 11 eram escotocromogênicas (31\%). Conforme a autora é mais comum se encontrar $M$. intracellulare com produçáo de pigmento na Amazônia do que em outras localidades.

O M. mucogenicum, quarta espécie mais isolada, é uma micobactéria recentemente caracterizada como sendo de crescimento rápido e um importante contaminante dos sistemas de distribuição de água de hospitais (Goldblatt \& Ribes, 2002).

O M. lentiflavum é uma micobactéria descrita no ano de 1996 e isolada de amostras clinicas (Springer et al., 1996). Fenotipicamente é caracterizada como sendo de crescimento lento e escotocromogênica, que segundo Leão et al. (2004) náo tem sido isolada de meio ambiente. Entretanto, trabalho realizado por Kanai (2006) constatou a presença de $M$. lentiflavum em águas do Ribeirão do Feijão (dois isolados) e na estação de tratamento de água de São Carlos/SP/Brasil (28 isolados). Em Manaus, já foi identificado em isolados depositados na coleção de micobactérias do INPA, oriundos de amostras clínicas de pacientes com suspeita de tuberculose (Ogusku et al., 2007).

Pelo método molecular de PRA somente a amostra de água da torneira 2, coletada no dia 14/09/2007 (Tabela 3) foi positiva, correspondendo aquela onde obteve-se pelo isolamento quantitativo superior a 100 colônias. Nessa amostra, o DNA detectado no sedimento teve correspondência com as bandas da espécie isolada pelo cultivo (Figura 1). Nas demais amostras, tanto as que tiveram ou náo isolamento em cultivo, a técnica de PRA mostrou-se ineficaz, provavelmente devido ao número reduzido de bacilos álcool-ácido resistentes (UFC - unidades formadoras de colônias) nas amostras analisadas. Nesse sentido deve ser salientado que a técnica de PRA, desde a sua descrição por Telenti (1993), foi idealizada para a identificação de micobactérias a partir de colônias isoladas em meio de cultivo. Entretanto, com a evolução científica da técnica, se estuda seu uso diretamente nas amostras buscando acelerar a identificação das espécies de micobactérias (Silva et al., 2001). Além disso, e conforme Cortelli et al. (2003), o número de UFC presente na amostra é vital para que as técnicas moleculares apresentem positividade. Por este motivo muitos autores submetem o produto amplificado a um novo ciclo de amplificação, aumentando assim a chance de detecção do microrganismo em estudo (Zambon \& Haraszthy, 1995). Assim, no presente trabalho e devido à reduzida quantidade de bacilos, é possível que a não amplificação do DNA micobacteriano dos sedimentos das amostras seja devida ao tipo de protocolo utilizado. Nesse sentido tem-se uma vasta literatura que utiliza diversos métodos de amplificação e consequentemente, apresentam percentuais diferentes de positividade na detecção do DNA micobacteriano (Ogusku, 1998; Leão et al., 2004). Mediante o exposto, se faz necessário que novos protocolos de amplificação sejam testados para que se possa indicar o mais eficaz para a detecção de DNA micobacteriano em amostras ambientais.

Diversos trabalhos demonstram que algumas espécies de MA têm na água o seu habitat natural (Schulze-Robbecke et al., 1992; Granucci, 2001; Gerba et al., 2003). Evidências de que na água as MA podem crescer e se manter nos sistemas de distribuição de ambientes hospitalares tem sido também descritas (Von Reyn et al., 1993; Von Reyn et al., 1994; Le Dantec et al., 2002). 


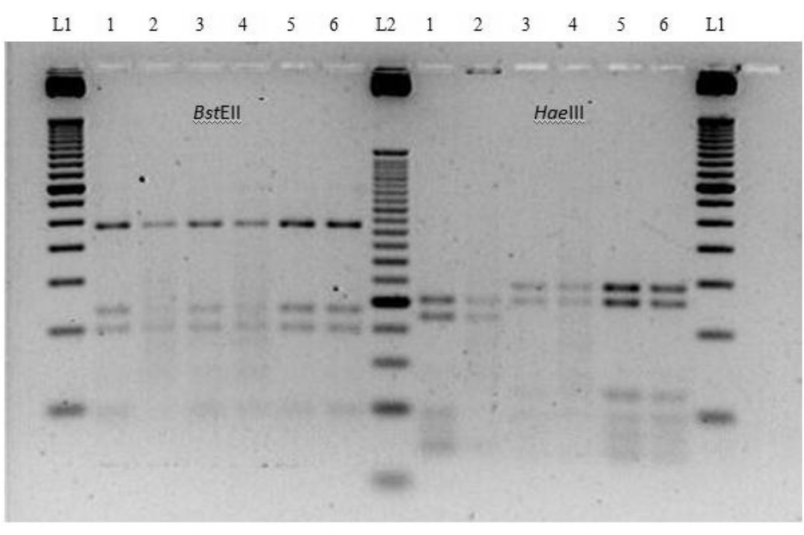

Figura 1 - Perfil de algumas espécies micobacterianas após digestão de fragmentos de DNA (hsp65) com enzimas de restrição BstEll e Hae III. L1, ladder 50 pares de bases; L2, ladder 25 pares de bases; 1 e 2, M. gordonae (perfil 3); 3 e 4, M. lentiflavum (perfil 3); 5 e 6 , M. intracellulare (perfil 1).

Alguns autores consideram que a existência de micobactérias nos sistemas de distribuição de água pode ser a forma de infectividade do ser humano (Von Reyn et al., 1993; Von Reyn et al., 1994; Le Dantec et al., 2002), fato esse amparado no reconhecimento das micobactérias como patógenos oportunistas (Vaerewijck et al., 2005). Assim, pacientes debilitados e/ou com soluçóes de continuidade na derme, estariam mais expostos a adquirir micobacterioses em ambientes hospitalares com sistema de distribuição de águas contaminados por micobactérias ambientais.

Falcáo et al. (1993), analisando amostras de água provenientes de diversas fontes, verificaram que os únicos organismos potencialmente patogênicos, encontrados em amostras de água tratada e de nascentes, eram micobactérias ambientais. Esse fato encontra respaldo nos achados de Miyamoto et al. (2000), em que isolados de Mycobacterium spp sobreviveram à exposição ao cloro em concentração de $4 \mathrm{mg} / \mathrm{L}$ por mais de 60 minutos, e nos de Vaerewijck et al. (2005), em que as MA têm a capacidade de crescimento em baixas concentrações de nutrientes, formaçâo de biofilme e interaçôes com protozoários. Além disso, e de acordo com Kazda (1983), o nível de pureza das águas é importante para a proliferação de micobactérias, que crescem mal onde há grande numero de outros microrganismos.

Mediante o exposto e tendo como premissa que as águas de redes de distribuição pública são submetidas a tratamento, contém cloro e baixas concentrações de nutrientes que inibem o desenvolvimento de outros microrganismos, é coerente deduzir que os fatores relatados podem manter as micobactérias viáveis em redes de distribuição de água, inclusive em água de torneiras.

Das espécies isoladas (Tabela 4) os $M$. celatum, $M$. intracellulare e $M$. mucogenicum se destacam por suas importâncias na etiologia de micobacterioses e devido aos achados de isolamento em águas de torneiras de ambiente hospitalar (Covert et al., 1999). Tais espécies estáo classificadas como potencialmente patogênicas e tem sido implicadas em diversos surtos de infecçóes nosocomiais, sendo a água indicada como responsável pela contaminaçấo dos pacientes (Engel et al., 1980). Recentemente, trabalho realizado por Shin et al. (2007), relata surtos de infecçóes por M. mucogenicum após procedimentos cirúrgicos e em pacientes submetidos a hemodiálises.

O surto de micobacteriose em pacientes submetidos "a processos cirúrgicos ou cirúrgico-endoscópicos, ou ainda, que se infectaram a partir da disseminação do patógeno originário de um sítio cirúrgico à distância”, ocorrido no Rio de Janeiro/Brasil (Brasil/MS, 2007), ocasionado pelas espécies $M$. abscessus e fortuitum é um exemplo de ausência de controle de micobactérias nas águas, matérias, soluçôes e instrumentos utilizados em ambientes cirúrgicos. Desses, à água é dada a menor importância como uma possível fonte de contaminação nosocomial de micobacteriose. Entretanto nas águas tratadas e utilizadas em moradias, indústrias e hospitais, as referidas espécies são reconhecidas como uma importante fonte de micobactérias, e consideradas como o reservatório principal para a maioria de surtos e pseudo surtos nosocomiais (Wallace-Jr et al., 1998). Ambas as espécies não foram isoladas no presente trabalho, porém outras de igual importância em surtos como M. celatum, $M$. intracellulare e M. mucogenicum estấo presentes nas águas de serventia do Hospital Universitário Getúlio Vargas.

\section{CONCLUSÕES}

O não isolamento de micobactérias ambientais das soluçôes utilizadas para higienizaçấo das mãos dos cirurgiôes e nos procedimentos cirúrgicos, assim como das luvas usadas pelos cirurgiōes, no Hospital Universitário Getulio Vargas, indica que as soluçóes não possuem ou têm sido eficazes na eliminação de micobactérias, consequentemente na prevenção de micobacterioses que podem ser adquiridas devido aos procedimentos invasivos das cirurgias. Entretanto, a presença de $M$. mucogenicum nas águas das torneiras do centro cirúrgico do Hospital Universitário Getulio Vargas, espécie já incriminada em surtos pós-cirúrgicos, indica que devem ser efetuados procedimentos de limpeza e monitoramento em todos os pontos de distribuição de águas, visando à prevenção de surtos de micobacterioses nosocomiais induzidos pelo uso das águas nas diferentes atividades de manuseio ou higienização dos pacientes submetidos a procedimentos invasivos.

\section{AGRADECIMENTOS}

Ao CNPq pela concessão de bolsa e a Fundação de Amparo a Pesquisa do Estado do Amazonas pelo apoio financeiro (Processo no 981/05). 


\section{BIBLIOGRAFIA CITADA}

Bermúdez, P.; Colmenero, J.D.E.D.; Lopez, J.J.; Baron, M.A. 2001. Disseminated infection due to Mycobaterium celatum. Enfermedades Infecciosas y Microbiologia Clinica, 19(7): 349350.

Bland, C.S.; Ireland, J.M.; Lozano, E.; Alvarez, M.E.; Primm, T.D. 2005. Mycobacterial Ecology of the Rio Grande. Applied and Environmental Microbiology, 71(10): 5719-5725.

Brasil. Ministério da Saúde. Secretaria de Vigilância em Saúde. Centro de Referencia Prof. Helio Fraga. 2005. Manual de Bacteriologia da Tuberculose / Ministério da Saúde, Secretaria de Vigilância em Saúde, Centro de Referencia Prof. Helio Fraga, Departamento de Vigilância Epidemiológica, Coordenação Geral de Laboratórios de Saúde Publica. $3^{\mathrm{a}}$ ed. Edição comemorativa Rio de Janeiro. 240pp.

Brasil/MS. Ministério da Saúde. Secretaria de Vigilância em Saúde. Departamento de Vigilância Epidemiológica. Nota técnica no 03/07 - SESA/SVS. 2007. Ocorrência de surto de infecçóes por Mycobacterium não tuberculosis pós-cirurgicas no Rio de Janeiro/ RJ.

Brunello, F.; Ligozzy, M.; Cristelli, E.; Bonora, S.; Tortoli, E.; Fontana, R. 2001. Identification of 54 mycobacterial species by PCR-restriction fragment length polymorphism analysis of the hsp65 gene. Journal of Clinical Microbiology, 39(8): 27992806.

Casal, M. 2003. Cómo denominar a las micobacterias diferentes a Mycobacterium tuberculosis y a M. leprae. Enfermedades Infecciosas y Microbiologia Clinica, 21(6): 296-8.

Cortelli, S.C.; Jorge, A.O.C.; Cortelli, J.R. 2003. Estudo da correlação Actinobacillus actinomycetemcomitans e bolsas periodontias profundas. Revista Periodontia, 13(7): 20-25.

Costa Cruz, J. 1938. Mycobacterium fortuitum um novo bacilo acido resistente patogênico para o homem. Acta Médica, 1(4): 297-301.

Covert, T.C.; Rodgers, M.R.; Reyes, A.L.; Stelma-Jr, G.N. 1999. Occurrence of Nontuberculous mycobacteria in environmental samples. Applied and Environmental Microbiology, 65(6): 24922496.

Dalcolmo, M.P. 2007. Epidemia de micobacteriose não tuberculosas de crescimento rápido (MNTB) no estado do Rio de Janeiro. Informe Sobracil - RJ, Março/Abril: 1-2.

David, H.L.; Levy-Frebault, V.; Thorel, M.F. 1989. Mèthodes de Laboratoire pour Mycobactériologie Clinique. Comission des Laboratoires de Reference et D'Expertise de L'Institute Pasteur, França. 88pp.

Devallois, A.; Khye, S.G.; Nalin, R. 1997. Rapid Identification of Mycobacteria to Species Level by PCR-Restriction Fragment Length Polymorphism Analysis of the hsp65 Gene and Proposition of an Algorithm to Differentiate 34 Mycobacterial Species. Journal of Clinical Microbiology, 35(11): 2969-2973.

Edwards, L.B.; Palmer, C.E. 1959. Isolation of "Atypical" Mycobacteria from Healthy Persons. American Review of Respiratory Disease, 80: 747-749.
Ellner, P.D.; Kiehn, T.E.; Cammarata, R.; Hosmer, M. 1988. Rapid detection and identification of pathogenic mycobacteria by combining radiometric and nucleic acid probe methods. Journal of Clinical Microbiology, 26(7): 1349-1352.

Engel, H.W.B.; Berwald, L.G.; Havelaar, A.H. 1980. The occurrence of Mycobacterium kansasii in tap water. Tubercle, 61: 21-26.

Falcão, D.P.; Valentini, S.R.; Leite, C.Q.F. 1993. Pathogenic or potentially pathogenic bacteria as contaminants of fresh water from different sources in Araraquara, Brazil. Water Resources, 27(12): 1737-1741

Foz, A.; Roy, C.; Jurado, J.; Arteaga, E.; Ruiz, J.; Moragas, A. 1978. Mycobacterium chelonei Iatrogenic Infections. Journal of Clinical Microbiology, 7(3): 319-321.

Gerba, C.P.; Nwachuku, N.; Rilley, K.R. 2003. Desinfection resistance of waterborne pathogens on the United States Environmental Protection Agency's Contaminant Candidate List (CCL). Journal of Water Supply: Research and Technology. Aqua, 52(2): 81-94.

Goldblatt, M.R.e Ribes, J.A. 2002. Mycobacterium mucogenicum isolated from a patient with Granulomatous Hepatitis. Archives of Pathology and Laboratory Medicine, 126(1): 73-75.

Granucci, G.F. 2001. Estudo das micobactérias veiculadas pelas águas da regiáo de Itápolis - SP. Dissertação de Mestrado, Instituto de Biociências, Universidade Estadual Paulista, Rio Claro, São Paulo. 89p.

Gremillion, D.H.; Mursch, S.B.; Lerner, C.J.; 1983. Injection site abscesses caused by Mycobacterium chelonei. Infection Control, 4(1): 25-28.

Kanai, K.Y. 2006. Deteç̧ão e identificação de micobacterias em corpos de água destinados a captação para abastecimento urbano da cidade de são Carlos-SP. Dissertação de Mestrado, Faculdade Ciências Ambientais, Universidade Federal de São Carlos, São Carlos, São Paulo. 88pp.

Kazda, J.F. 1983. The principles of the ecology of mycobacteria. In: Ratledge, C.; Stanford, J. The Biology of mycobacteria. London: Academic Press. 406pp.

Le Dantec, C.; Duguet, J.P.; Montiel, A.; Dumoutier, N.; Dubrou, S.; Vincent, V. 2002. Occurrence of Mycobacteria in water treatment lines and in water distribution systems. Applied Environmental Microbiology, 68(11): 5318-5325.

Leão, S.C.; Martin, A.; Mejia, G.I.; Palomino, J.C.; Robledo, J.; Telles, M.A.S.; Portaels, F. 2004. Practical Handbook for the phenotypic and genotypic identification of mycobacteria. 164pp.

Leão, S.C.; Bernardelli, A.; Cataldi, A.; Zumarraga, M.; Robledo, J.; Realpe, T.; Mejia, G.I.; Da Silva, T.M.A.; Chimara, E.; Velazco, M.; Fernandez, J.; Araya, R.P.; Guerrero, M.I.; Leon, C.I.; Porras, T.B.; Rastogi, N.; Seng, G.K.; Suffys, P.; Da Silva, R.A.; Dos Santos, N.D.; Ritacco, V.; Lopez, B.; Barrera, L.; Palomino, J.C.; Martinl, A.; Portaels, F. 2005. Multicenter evaluation of mycobacteria identification by PCR restriction enzyme analysis in laboratories from Latin America and the Caribbean. Journal of Microbiological Methods, 61(2): 193-199.

Leite, C.Q.; De Souza, C.W.; Leite, S.R. 1998. Identification of mycobacteria by thin layer chromatographic analysis of mycolic 
acids and conventional biochemical method: four years of experience. Memórias do Instituto Oswaldo Cruz, 93(6): 801805.

Lopes, M.L.; Lima, K.V. B.; Leão, S.; Sousa, M. S.; Santi, L.; Loureiro, E.C.B. 2005. Micobacterioses associadas a procedimentos médicos invasivos em Belém. Revista Paraense de Medicina, 19(2): 87-89.

Mackay, W.G.; Leanord, A.T.; Williams, C.L. 2002. Water, water everywhere nor any a sterile drop to rinse your endoscope. Journal of Hospital Infection, 51(4):256-261.

Miyamoto, M.; Yamaguchi, Y.; Sasatsu, M. 2000. Disinfectant effects of hot water, ultraviolet light, silver ions and chlorine on strains of Legionella and Nontuberculous mycobacteria. Microbiologia, 101(398): 7-13.

Neumann, M.; Schulze-Röbbecke, R.; Hagenau, C.; Behringer, K. 1997. Comparison of method for isolation of mycobacteria from water. Applied Environmental Microbiology, 63(2): 547-552.

Ogusku, M.M. 1998. Utilização da técnica de reação em cadeia da polimerase (PCR) no diagnóstico laboratorial da tuberculose cutânea. Dissertação de Mestrado, Instituto de Ciências Biomédicas, Universidade de São Paulo, São Paulo. 71p.

Ogusku, M.M.; Okamura, L.H.; Salem, J.I. 2007. Espécies de Micobacterias isoladas de amostras clinicas de indivíduos com suspeita de tuberculose. Resumos do $24^{\circ}$ Congresso Brasileiro de Microbiologia, Brasília.

Ordiz-Oviedo, Ignácio. Efectos Secundários de la Mesoterapia: Las Infecciones Cutáneas (www.ordizmesoterapia.com/articulos/ Las-infecciones cutaneas.pdf). Acesso: 01/06/06.

Pai, S.; Esen, N.; Pan, X.; Musser, J.M. 1997. Routine rapid Mycobacterium species assignment based on species-specific allelic variation in the 65-kilodalton heat shock protein gene (hsp65). Archives of Pathology and Laboratory Medicine, 121(8): 859-864.

Phillips, M.S.; Von Reyn, C.F. 2001. Nosocomial Infections Due to Nontuberculous Mycobacteria. Clinical Infectious Diseases, 33(8): 1363-74.

Ruiz Manzano, J.; Manterola, J.M.; Ausina, V.; Sauret, J. 1998. Nomenclatura y clasificación de las micobacterias. Archivos de Bronconeumología, 34(3): 154-7.

Ruiz, P.A.; Mederos-Cuervo, L.M. 1999. Micobacteriosis por Mycobacterium gordonae. Primer caso reportado en Cuba. Revista Cubana de Medicina Tropical, 51(2): 128-129.

Runyon, E.H.; Karlson, A.G.; Kubica, G.P.; Wayne, L.G. 1980. Mycobacterium, In: Lennette, E.H.; Balows, A.; Hausler, W.J.; Truant. J.P. (eds), Manual of Clinical Microbiology. 3a ed. Washington, D.C: American Society for Microbiology. 571pp.

Salem, J.I. 1987. Presença de micobactérias na pele e sua importância em lesóes cutâneas. Tese de Doutorado, Instituto de Microbiologia, Universidade Federal do Rio de Janeiro, Rio de Janeiro. $107 \mathrm{pp}$.

Salem, J.I.; Gontijo-Filho P.; Lévy-Frébault, V.; Davis, H. 1989a. Isolation and Characterization of Mycobacteria Colonizing the Healthy Skin. Acta Leprologica, 7(1): 18-30.
Salem, J.I.; Maroja, M.F.; Farias, C.F.; Otsuka, M.; Feuillet, A. 1989b. Mycobacteria Other Than Tubercle Bacilli in Sputum Specimens from Patients in Manaus (Amazônia, Brasil). Acta Amazonica, 19: 349-354.

Sampaio, J.L.M.; Chimara, E.; Ferrazoli, L.; Da Silva Telles, M.A.; Del Guercio, V.M.F.; Jerico, Z.V.N.; Miyashiro, K.; Fortaleza, C.M.C.B. Padoveze, M.C.; Leão S.C. 2006. Application of four molecular typing methods for analysis of Mycobacterium fortuitum group strains causing post-mammaplasty infections. Clinical Microbiology and Infection, 12(2): 142-149.

Schulze-Röbbecke, R.; Janning, B.; Fischeder, R. 1992. Ocurrence of mycobacteria in biofilm samples. Tubercle and Lung Disease, 73(3): 141-144.

Sethi, S.; Sharma, M.; Ray, P.; Singh, M.; Gupta, A. 2001. Mycobacterium fortuitum wound infection following laparoscopy. Indian Journal of Medical Research, 113: 83-84.

Shin, J.H.; Lee, E.J.; Lee, H.R.; Ryu, S.M.; Kim, H.R.; Chang, C.L.; Kim, Y.J.; Lee, J.N. 2007. Prevalence of non-tuberculous mycobacteria in a hospital environment. Journal of Hospital Infection, 65(2): 143-148.

Silva, C.F.; Ueki, S.Y.M.; Geiger, D.; Pires, D.C.; Leão, S. 2001. PCR e análise de padrôes de restrição do gene hsp 65 (PRA) para identificação de micobactérias no laboratório clínico. Revista do Instituto de Medicina Tropical de São Paulo, 43(1): 25-28.

Springer, B.; Stockman, L.; Teschner, K.; Roberts, G.D.; Böttger, E.C. 1996. Two-laboratory collaborative study on identification of mycobacteria: molecular versus phenotypic methods. Journal of Clinical Microbiology, 34(2): 296-303.

Telenti, A.; Marchesi, F.; Balz, M.; Bally, F.; Botrger, E.C.; Bodmer. T. 1993. Rapid identification of mycobacteria to the species level by polymerase chain reaction and restriction enzyme analysis. Journal of Clinical Microbiology, 31(2): 175-178.

Tsukamura, M. 1966. Adansonian classification of mycobacteria. Journal of General Microbiology, 45(2): 253-273.

Vaerewijck, M.J.M.; Geert, H.; Palomino, J.C.; Swings, J.; Portaels, F. 2005. Mycobacteria in drinking water distribution systems: ecology and significance for human health. FEMS Microbiology Reviews, 29(5): 911-934.

Von Reyn, C.F.; Waddell, R.D.; Eaton, T.; Arbeit, R.D.; Maslow, J.N.; Barber, T.W.; Brindle, R.J.; Gilks, C.F.; Lumio, J.; Lahdevirta, J.; Ranki, A.; Dawson, D.; Falkinham, J.O. 1993. Isolation de $M$. avium complex from water in the United States, Finland, Zaire, and Kenya. Journal of Clinical Microbiology, 31(12): 3227-3230.

Von Reyn, C.F.; Maslow, J.N.; Barber, T.W.; Falkinham, J.O.; Arbeit, R.D. 1994. Persistent colonization of potable water as a source of Mycobacterium avium infection in AIDS. The Lancet, 343(8906): 1137-1141.

Wallace-Jr, R.J.; Brown, B.A.; Griffith, D.E. 1998. Nosocomial outbreaks/pseudo-outbreaks caused by nontuberculous mycobacteria. Annual Review of Microbiology, 52: 453-490.

WHO - WORLD HEALTH ORGANIZATION. 1998. Laboratory services in tuberculosis control, Part III Culture. Geneva, Publication No. WHO/TB/98. 258pp. 
Winthrop, K.L; M Abrams, M.; Yakrus, M.; Schwartz, I.; Ely, J. 2002. An outbreak of mycobacterial furunculosis associated with footbaths at a nail salon. The New England Journal of Medicine, 346(18): 1266-1371.

Zambon, J.J, Haraszthy, V.I. 1995. The laboratory diagnosis of periodontal infections. Periodontology, 7(1): 69-82.

Recebido em 21/01/2008

Aceito em 30/07/2009 
